\title{
Nitrogen Release in Pristine and Drained Peat Profiles in Response to Water Table Fluctuations: A Mesocosm Experiment
}

\author{
Merjo P. P. Laine, ${ }^{1}$ Rauni Strömmer, ${ }^{1}$ and Lauri Arvola ${ }^{2}$ \\ ${ }^{1}$ Section of Environmental Ecology, Department of Environmental Sciences, University of Helsinki, Niemenkatu 73, 15140 Lahti, Finland \\ ${ }^{2}$ Lammi Biological Station, University of Helsinki, Pääjärventie 320, 16900 Lammi, Finland \\ Correspondence should be addressed to Merjo P. P. Laine; merjo.laine@helsinki.fi
}

Received 23 July 2013; Accepted 2 October 2013

Academic Editor: Ryusuke Hatano

Copyright (C) 2013 Merjo P. P. Laine et al. This is an open access article distributed under the Creative Commons Attribution License, which permits unrestricted use, distribution, and reproduction in any medium, provided the original work is properly cited.

In the northern hemisphere, variability in hydrological conditions was suggested to increase as a consequence of climate warming, which may result in longer droughts than the area has experienced before. Due to their predominately anoxic conditions, peatlands are expected to respond to changes in hydrological conditions, such as successive drying and rewetting periods. As peatlands are rich in organic matter, any major changes in water table may influence the decomposition of it. The hydrological conditions may also influence release of nutrients from peat profiles as well as affect their transport to downstream ecosystems. In our mesocosm experiment, artificial water table fluctuations in pristine peat profiles caused an increase in dissolved organic nitrogen (DON) and ammonium $\left(\mathrm{NH}_{4}{ }^{+}-\mathrm{N}\right)$ concentrations, while no response was found in drained peat profiles, although originating from the same peatland complex.

\section{Introduction}

High latitudes are expected to experience considerable climatic warming during the 21st century [1]. As a response to climatic change, the position of the water table in boreal and subarctic peatlands will be modified [2], and heavy precipitation events and number of wet days are expected to increase in northern Europe [3]. Climate change predictions for northern Europe, and specifically for Finland, indicate an increase in precipitation by $5-40 \%$ and in air temperature by $2-7$ degrees Celsius $\left({ }^{\circ} \mathrm{C}\right)$ by the 2080 s, depending on the climate model and scenario used [4].

Variation in hydrological processes in both space and time causes changes in nutrient transport from land to surface waters [5]. Modelling studies predict that plausible high climate change scenarios will increase the annual $\mathrm{N}$ fluxes in small, forested watersheds in Finland. Increase in 30 years in dissolved inorganic nitrogen can be as high as $25 \%$ [6]. Holmberg et al. [7] predicted that an increase in total nitrogen load in 40 years can be $26 \%$.

Studies concerning the effects of fluctuating water table on $\mathrm{N}$ compounds and their concentrations in soil water in peatlands are scarce. Even though anaerobic bacteria are involved in the nitrogen cycle in various ecosystems [8], N mineralization in peatlands is usually more effective in aerobic than in anaerobic conditions and not least in bogs [9].

Therefore, rewetting after a dry period brings an interesting aspect for understanding nutrient dynamics in a changing climate. Also at high latitudes, where annual rainfall is predicted to increase, there may be heavy rainfall events which follow exceptionally dry seasons. For example, in Finland during the summer months (June-August) in 2006, the monthly average rainfall was $75 \%$ or less as compared to the average summer rainfall in 1961-2006, but in October 2006 the amount of rainfall was even $250 \%$ of the average October rainfalls in the years of comparison 1971-2000 (Finnish Meteorological Institute).

Even though lowering water table is likely to accelerate nitrogen cycling, it is, however, difficult to predict the change in concentration of certain nitrogen compounds since different processes of $\mathrm{N}$ cycle are functioning simultaneously. Furthermore, changes in redox conditions complicate predictions. Therefore, it is not peculiar that results concerning 
effects of various environmental changes on $\mathrm{N}$ compounds in soil water in peatlands can be contradictory [10-12].

Catchment level knowledge about element fluxes is crucial as the fluxes of nutrients from terrestrial areas end up in lakes and rivers and eventually in seas and oceans. It is especially important to study this in boreal areas where the expected change in climate is considerable. More detailed information from different ecosystems is needed in order to achieve comprehensive understanding about nutrient dynamics on a catchment scale.

For example, in Finland 29 percent of the land area is peatlands, and 53 percent of the Finnish peatlands is drained [13]. Therefore, it is important to compare nutrient dynamics of boreal pristine and drained peatlands. We performed an artificial water table manipulation mesocosm study with peat profiles originating these peat types. We studied a release of different fractions of nitrogen, that is, dissolved organic nitrogen (DON), ammonium-nitrogen $\left(\mathrm{NH}_{4}{ }^{+}-\mathrm{N}\right)$, and nitrite + nitrate-nitrogen $\left(\mathrm{NO}_{2}{ }^{-}+\mathrm{NO}_{3}{ }^{-}-\mathrm{N}\right)$, from pristine and drained peat profiles. We hypothesized that rewetting after a dry period releases nutrients into soil water and the response for fluctuating water table for nutrient release is stronger in pristine peat type, because the aerobic process rates are slower in premise. Therefore, in pristine peat there is more organic nitrogen, which can be released as such or it can be mineralized and released into soil water as inorganic compounds.

\section{Materials and Methods}

2.1. Site Description. The pristine and drained peat profiles for the mesocosm experiment were collected from a peatland complex, Laaviosuo, Southern Finland. The peatland type of the pristine area $\left(61^{\circ} 01^{\prime} 48^{\prime \prime} \mathrm{N}, 25^{\circ} 01^{\prime} 38^{\prime \prime} \mathrm{E}, 151 \mathrm{~m}\right.$ a.s.l.) was classified as oligotrophic Eriophorum vaginatum pine bog according to Eurola et al. [14]. The peat is composed mainly of Carex with a decomposition rate of $\mathrm{H} 4$ according to the von Post scale [15] at $30 \mathrm{~cm}$ and $50 \mathrm{~cm}$ depths. There are 10 levels ( $\mathrm{H} 1-\mathrm{H} 10)$ in the von Post peat decomposition scale, $\mathrm{H} 10$ being the most decomposed one. $\mathrm{H} 4$ peat releases murky water, but peat does not come through fingers when squeezed. The piece of the peat that is in hand after squeezing keeps its shape. Peat cores for the experiment were collected on June 2, 2009, from treeless low tussock places, which were dominated by Vaccinium oxycoccos, Eriophorum vaginatum, and Carex lasiocarpa.

The other part of the complex $\left(61^{\circ} 02^{\prime} 05^{\prime \prime} \mathrm{N}\right.$, $25^{\circ} 00^{\prime} 37^{\prime \prime} \mathrm{E}$, $149 \mathrm{~m}$ a.s.1.) was drained in 1978 , and the type of this part was classified as peated dwarf shrub heath [14]. Presently the area is covered by 5-10 meters tall Scots pines (Pinus sylvestris), and the peat is composed mainly of Sphagnum with a decomposition rate of H5 [15] at 30 and $50 \mathrm{~cm}$ depths, while a more decomposed layer was present at a depth of $20 \mathrm{~cm}$. H5 peat releases very murky water and a little bit of peat through fingers when squeezed. The piece of the peat left in hand after squeezing does not keep its shape very well. Peat cores were collected on June 2-3, 2009, from places of treeless low tussocks dominated by Eriophorum vaginatum and Bryopsida mosses. In dry summers there

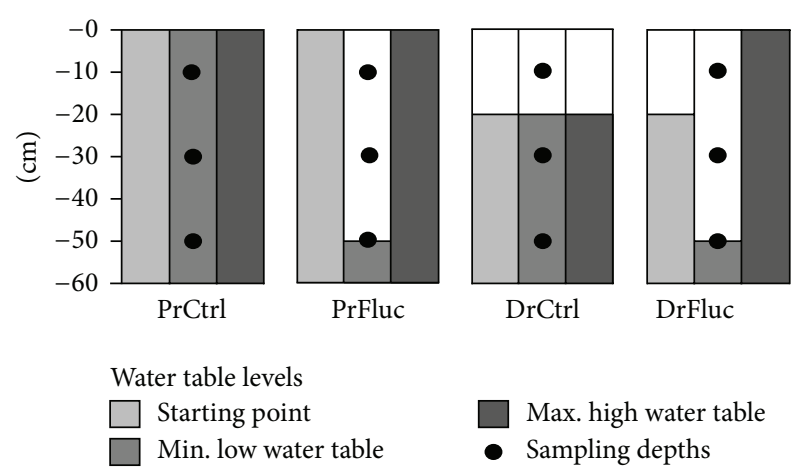

FIGURE 1: Schematic presentation of the mesocosms. Pr = pristine, $\mathrm{Dr}=$ drained, $\mathrm{Ctrl}=$ control, and Fluc = fluctuating water table.

is hardly any surface outflow in the experimental areas, so the groundwater level is tens of centimeters below the soil surface. Instead, the surface outflow in rainy periods indicates that the groundwater surface is at the soil surface or very close to it.

The experiment represents extreme but still realistic precipitation conditions. Precipitation data was provided by the Finnish Meteorological Institute. The measuring station (Hämeenlinna, Pappila), where the hourly data was recorded, locates at Lammi Biological Station (LBS). The LBS data showed monthly average precipitation (excluding snowfall in October 1992) of $0.8-3.3 \mathrm{~mm} \mathrm{~d}^{-1}$. Monthly maximum values in September-October in 1989-1998 (without the snowfall) were $8.5-21.5 \mathrm{~mm} \mathrm{~d}^{-1}$. The mesocosms stayed unfrozen during the whole experiment, although the first hours of the autumn with temperature going under zero degrees Celsius, occurred on September 29, 2009.

2.2. Mesocosm Settings. 20 plastic cylinders with a diameter of $24 \mathrm{~cm}$ and a height of $60 \mathrm{~cm}$ were used for establishing the peat profiles. The outer surface of each container was painted white to prevent warming due to direct solar radiation. In order to take water samples, the containers had small holes blocked up with rubber plugs at depths of $-10 \mathrm{~cm}$, $-20 \mathrm{~cm},-30 \mathrm{~cm}$, and $-50 \mathrm{~cm}$ from top to bottom (Figure 1). In addition, a transparent plastic tube $(\varnothing 10 \mathrm{~cm})$ was installed from bottom to top alongside the outer wall of each container to follow the water table.

For each mesocosm, a large piece of peat was dug (dug in two parts) from peatland and then carved smaller to fit into a container. As a result of placing the piece into the container as it was vertically in peatland, a peat profile mesocosm was founded. The aboveground vegetation was left intact, so vegetation that came along with the dug and carved peat block was on the top of the mesocosms during the whole experiment as it was naturally in peatland. At the beginning of the experiment, the topmost layer of peat was at the level of the container edge, but later on the peat went down from a half to five centimetres, except in one mesocosm (DrFluc, see next), where peat went down eight centimetres. All mesocosms were placed into an unheated greenhouse at LBS close to Laaviosuo. 
The mesocosms were randomized and divided into two treatments, control (Ctrl) and fluctuating water table (Fluc), differing in their temporal-magnitude variation of water table. Altogether, there were four mesocosm groups: pristine peat profiles with control conditions (PrCtrl), pristine peat profiles with fluctuating water table (PrFluc), drained peat profiles with control conditions (DrCtrl), and drained peat profiles with fluctuating water table (DrFluc). The water table in the peatland potholes was measured on the next day after digging the peat cores, and it was considered as a control hydrologic condition. In the pristine peatland the control water table was at the level of the peat surface, while in the drained peatland the water table was at $-20 \mathrm{~cm}$ depth. At first (June $3-10,2009$ ) the water table was adjusted in all mesocosms to their control level (Figure 1), and in the controls the water table was kept at their initial levels through the experiment. To achieve this, we added water to the mesocosms on regular basis. The added water was taken from a groundwater spring (Löytynlähde, $61^{\circ} 02^{\prime} 53^{\prime \prime} \mathrm{N}, 24^{\circ} 58^{\prime} 32^{\prime \prime} \mathrm{E}$ ) close to Laaviosuo. Spring water was used because of its stable chemical composition, but also because natural peatlands receive groundwater as well.

2.3. Manipulations and Samplings. Two successive water table manipulations were performed for Fluc mesocosms indicating low and high water tables. During the first period (June 11-September 20,2009) only a small amount of water was added to the mesocosms in order to keep the plants alive. At the beginning of this period (June 11-June 26, 2009) $500 \mathrm{~mL}$ water was released from the bottommost hole of the pristine mesocosms and $400 \mathrm{~mL}$ from the drained mesocosms. In addition, water was lost by evapotranspiration and later on in samplings. In September 21-October 30, 2009, the second period was performed. At the beginning of it, two litres of water were added three times a week until the Fluc mesocosms were saturated with water (see Figure 1). Once the desired water table was reached, water was added occasionally to maintain this level. Five days without adding water preceded all water samplings to avoid disturbance. Magnitude of the water addition was estimated on the basis of the precipitation data provided by the Finnish Meteorological Institute. The measured volumes of realized water additions were reported before and during the high water table period, and the volumes were also converted to corresponding precipitation $\left(\mathrm{mm} \mathrm{d}^{-1}\right)$ (Table 1$)$. As the physical structure of peat was different in pristine and drained profiles and we wanted to keep the profiles as natural as possible without any homogenization, their water keeping capacities were different. As water table defines the aerobic/anaerobic conditions of the soil, we chose to use the target water levels instead of standard water volume additions to the mesocosms, and as a consequence, the amount of added water varied among the mesocosms (Table 1).

Water samples were taken from both Ctrl and Fluc mesocosms once at the end of the first period, that is, at the end of the low water table (phase 0) on September 11, 2009, and four times during the second period, that is, during the high water table on October 2, 16, 23, and 30, 2009 (phases 1, 2, 3, and 4). Samples were taken through the container holes using
$0.15 \mu \mathrm{m}$ porous lysimeters (Eijkelkamp Agrisearch Equipment 192121, Rhizon soil moisture sampler, type MOM). pH samples were taken by syringes, leaving the samples unfiltered. In DrCtrl mesocosms sampling depths were $-20 \mathrm{~cm}$, $-30 \mathrm{~cm}$, and $-50 \mathrm{~cm}$ (Figure 1). In all other mesocosms sampling depths were $-10 \mathrm{~cm},-30 \mathrm{~cm}$, and $-50 \mathrm{~cm}$. Water from the three depths was pooled for a composite sample. At phase 0 the sample volume was not enough for all water analyses.

2.4. Laboratory Analyses. DON, $\mathrm{NH}_{4}^{+}-\mathrm{N}$, and $\mathrm{NO}_{2}^{-}{ }^{-}$ $\mathrm{NO}_{3}{ }^{-}-\mathrm{N}$ concentrations of the filtered samples and $\mathrm{pH}$ of the unfiltered samples were measured from both Ctrl and Fluc mesocosms using standard methods of LBS laboratory protocols. DON was analysed with a QuickChem method 10-107-04-1-I (detection limit $40 \mu \mathrm{g} \mathrm{L}^{-1}$ ), $\mathrm{NH}_{4}{ }^{+}-\mathrm{N}$ with a QuickChem method 10-107-06-1-F (detection limit $5 \mu \mathrm{g} \mathrm{L}{ }^{-1}$ ), and $\mathrm{NO}_{2}{ }^{-}+\mathrm{NO}_{3}{ }^{-}-\mathrm{N}$ with a QuickChem method 10-107-041-B (detection limit $5 \mu \mathrm{g} \mathrm{L}^{-1}$ ) with a Lachat QuickChem 8000 FIA nutrient analyzer. All of those concentrations in samples were above the detection limit. Water $\mathrm{pH}$ was measured with an Orion $\mathrm{pH}$ meter. The chemistry of the spring water was analysed in 2009 and 2011.

2.5. Statistical Analyses. Differences between experimental groups (PrCtrl, PrFluc, DrCtrl, and DrFluc) and between phases and interactions between them on $\mathrm{DON}, \mathrm{NH}_{4}{ }^{+}-\mathrm{N}$, and $\mathrm{NO}_{2}{ }^{-}+\mathrm{NO}_{3}{ }^{-}-\mathrm{N}$ were tested by using SAS 9.2./Proc mixed with repeated statement method [16]. Different models with different covariance structures are used in the program, and for choosing the most proper covariance structure, AIC values of different models were compared and the structure with the lowest AIC was chosen. The chosen covariance structures were Toeplitz in analysing DON, unstructured in $\mathrm{NH}_{4}{ }^{+}-\mathrm{N}$, and heterogeneous autoregressive in $\mathrm{NO}_{2}{ }^{-}+$ $\mathrm{NO}_{3}{ }^{-}-\mathrm{N}$. When the experimental group effect was significant, contrasts between the experimental groups (PrCtrl versus DrCtrl; PrFluc versus DrFluc; PrCtrl versus PrFluc, and DrCtrl versus DrFluc) were tested. Phase 0 results were not included in any of the statistical tests.

\section{Results}

DON concentrations were higher in DrCtrl than in PrCtrl and higher in PrFluc than in PrCtrl (Tables 2 and 3; Figure 2(a)). DON differed also between the different phases of the experiment (Table 2) mainly because of a decrease in DON concentration after phase one. During the dry period, we did not get enough water from the mesocosms to analyse DON. There were no interactions between the experimental groups and the phases of the experiment in any of the nitrogen fractions.

At the end of the low water table (phase 0), the mean concentration of $\mathrm{NH}_{4}{ }^{+}-\mathrm{N}$ was 1.5 times higher in PrFluc than in PrCtrl (Figure 2(b)). At the beginning of the following period, that is, high water table (phase 1 , that is, 11 days after starting the substantial watering), the mean concentration of $\mathrm{NH}_{4}^{+}-\mathrm{N}$ in PrFluc was 2.3 times higher than at phase 0 in the same mesocosms, that is, in PrFluc (Figure 2(b)). In 
TABLE 1: Spring water volumes added to each experimental group during the low water table (A) and high water table (B) periods within the five months' experiment.

\begin{tabular}{|c|c|c|c|c|c|}
\hline \multirow{2}{*}{ Experimental group and period } & & \multicolumn{2}{|c|}{ Added water (L) } & \multirow{2}{*}{$n$} & \multirow{2}{*}{ Mean $\mathrm{mm} \mathrm{d}^{-1}$} \\
\hline & & Mean & SE & & \\
\hline \multirow{2}{*}{ PrCtrl } & A & 8.7 & 0.8 & 5 & 1.9 \\
\hline & $\mathrm{B}$ & 2.1 & 0.1 & 5 & 1.1 \\
\hline \multirow{2}{*}{ PrFluc } & $\mathrm{A}$ & 2.5 & 0.0 & 5 & 0.5 \\
\hline & $\mathrm{B}$ & 11.9 & 1.3 & 5 & 6.4 \\
\hline \multirow{2}{*}{ DrCtrl } & A & 11.3 & 1.6 & 5 & 2.4 \\
\hline & B & 2.3 & 0.2 & 5 & 1.2 \\
\hline \multirow{2}{*}{ DrFluc } & $\mathrm{A}$ & 2.5 & 0.0 & 5 & 0.5 \\
\hline & $\mathrm{B}$ & 14.6 & 1.0 & 5 & 7.9 \\
\hline
\end{tabular}

Pr: pristine; Dr: drained; Ctrl: control; Fluc: fluctuating water table.

TABLE 2: Results of Proc mixed for $\mathrm{DON}, \mathrm{NH}_{4}{ }^{+}-\mathrm{N}$, and $\mathrm{NO}_{2}{ }^{-}+\mathrm{NO}_{3}{ }^{-}-\mathrm{N}$.

\begin{tabular}{|c|c|c|c|c|}
\hline & & Experimental groups & Phases & Interaction \\
\hline \multirow{4}{*}{ DON } & Num DF & 3 & 3 & 9 \\
\hline & Den DF & 16 & 46 & 46 \\
\hline & $F$ value & 5.06 & 9.85 & 0.72 \\
\hline & $P$ value & 0.0118 & $<0.0001$ & n.s. \\
\hline \multirow{4}{*}{$\mathrm{NH}_{4}^{+}-\mathrm{N}$} & Num DF & 3 & 3 & 9 \\
\hline & Den DF & 16 & 16 & 16 \\
\hline & $F$ value & 79.20 & 0.25 & 1.37 \\
\hline & $P$ value & $<0.0001$ & n.s. & n.s. \\
\hline \multirow{4}{*}{$\mathrm{NO}_{2}{ }^{-}+\mathrm{NO}_{3}{ }^{-}-\mathrm{N}$} & Num DF & 3 & 3 & 9 \\
\hline & Den DF & 16 & 48 & 48 \\
\hline & $F$ value & 2.78 & 2.02 & 1.92 \\
\hline & $P$ value & n.s. & n.s. & n.s. \\
\hline
\end{tabular}

The results present the fixed effects of experimental groups (PrCtrl, PrFluc, DrCtrl, and DrFluc), phases (1,2,3, and 4), and interaction of the experimental groups and phases. $N=5$ for each experimental group and each phase, except for DON at phases 3 and 4 in DrCtrl, where $n=4$. n.s.: nonsignificant.

contrary to $\mathrm{DON}, \mathrm{NH}_{4}{ }^{+}-\mathrm{N}$ concentrations were higher in PrCtrl than in DrCtrl (Tables 2 and 3; Figure 2(b)), while equal to $\mathrm{DON}, \mathrm{NH}_{4}{ }^{+}-\mathrm{N}$ was higher in PrFluc than in PrCtrl. $\mathrm{NH}_{4}{ }^{+}-\mathrm{N}$ concentrations were also higher in PrFluc than in DrFluc. $\mathrm{NH}_{4}{ }^{+}-\mathrm{N}$ in Fluc mesocosms in comparison to Ctrl mesocosms was 3.7 times higher in pristine and 3.0 times higher in drained peat mesocosms at phase 1 (see Figure 2(b)). There were no significant differences between phases (1-4) (Table 2).

$\mathrm{NO}_{2}{ }^{-}+\mathrm{NO}_{3}{ }^{-}-\mathrm{N}$ concentrations did not differ between the experimental groups or between the phases (1-4) (Table 2). Considerable variance in $\mathrm{NO}_{2}{ }^{-}+\mathrm{NO}_{3}{ }^{-}-\mathrm{N}$ concentrations was found between the replicates. Minimum and maximum $\mathrm{NO}_{2}{ }^{-}+\mathrm{NO}_{3}{ }^{-}-\mathrm{N}$ concentrations of the replicates at phases $1-4$ were 6 and $171 \mu \mathrm{g} \mathrm{L}^{-1}$ in PrCtrl, 10 and $29 \mu \mathrm{g} \mathrm{L}^{-1}$ in DrCtrl, 6 and $182 \mu \mathrm{g} \mathrm{L}^{-1}$ in PrFluc, and 7 and $283 \mu \mathrm{g} \mathrm{L}^{-1}$ in DrFluc.

DON, $\mathrm{NH}_{4}{ }^{+}-\mathrm{N}$, and $\mathrm{NO}_{2}{ }^{-}+\mathrm{NO}_{3}{ }^{-}-\mathrm{N}$ concentrations of spring water and min-max concentrations in mesocosms at phases $0-4$ are presented in Table 4 . It is remarkable that DON concentrations were higher in the mesocosm samples than in the spring water except in two mesocosm samples and that the mesocosm water showed up to three order of magnitude higher $\mathrm{NH}_{4}{ }^{+}-\mathrm{N}$ concentrations in comparison to the spring water. $\mathrm{NO}_{2}{ }^{-}+\mathrm{NO}_{3}{ }^{-}-\mathrm{N}$ concentrations in mesocosms stayed lower than in the spring water. Water $\mathrm{pH}$ varied in pristine peat mesocosms between 3.7 and 4.4 and in drained peat mesocosms between 3.1 and 3.7.

\section{Discussion}

We observed an increase in dissolved organic nitrogen (DON) concentrations during rewetting in pristine peat mesocosms, which is consistent with our hypothesis. However, similar phenomenon was not observed in the drained peat mesocosms. The higher DON concentrations in drained control than in pristine control mesocosms indicate that there has been overall better conditions for decomposition in drained than in pristine peatlands, which implies that organic nitrogen is largely in the form of macromolecules in pristine peat. We thus suggest that, in the drained peatland, decomposition has been effective for a long time under aerobic conditions. This is consistent with the general knowledge about the very basic mechanism of peatland formation, that peat 
TABLE 3: Contrasts between experimental groups for $\mathrm{DON}$ and $\mathrm{NH}_{4}{ }^{+}-\mathrm{N}$.

\begin{tabular}{|c|c|c|c|c|c|}
\hline & & PrCtrl versus DrCtrl & PrFluc versus DrFluc & PrCtrl versus PrFluc & DrCtrl versus DrFluc \\
\hline \multirow{3}{*}{ DON } & DF & 16 & 16 & 16 & 16 \\
\hline & $t$ value & 2.95 & 0.58 & 3.51 & 0.04 \\
\hline & $P$ value & 0.0094 & n.s. & 0.0029 & n.s. \\
\hline \multirow{3}{*}{$\mathrm{NH}_{4}{ }^{+}-\mathrm{N}$} & DF & 16 & 16 & 16 & 16 \\
\hline & $t$ value & 2.58 & 12.01 & 11.30 & 1.86 \\
\hline & $P$ value & 0.0201 & $<0.0001$ & $<0.0001$ & n.s. \\
\hline
\end{tabular}

$N=5$ for each group and phase, except for DON at phases 3 and 4 in DrCtrl, where $n=4$. Pr: pristine; Dr: drained; Ctrl: control; Fluc: fluctuating water table. n.s.: nonsignificant.

TABLE 4: Concentrations of nitrogen fractions in Löytynlähde spring water and the range (min-max) in the water samples from the mesocosms at phases $0-4$.

\begin{tabular}{lccc}
\hline & Löytynlähde & & Mesocosms \\
& & Min-max (phases 0-4) & $n$ (phases 0; 1-4) \\
\hline $\mathrm{DON}\left(\mu \mathrm{g} \mathrm{L}^{-1}\right)$ & $\leq 600$ (analysed 2009) & Min-max: 315-2181 & $0 ; 78$ \\
$\mathrm{NH}_{4}{ }^{-}-\mathrm{N}\left(\mu \mathrm{g} \mathrm{L}^{-1}\right)$ & $\leq 4$ (analysed 2009) & Min-max: 19-4041 & $14 ; 80$ \\
$\mathrm{NO}_{2}{ }^{-}+\mathrm{NO}_{3}{ }^{-}-\mathrm{N}\left(\mu \mathrm{g} \mathrm{L}^{-1}\right)$ & 600 (analysed 2009) & Min-max: 6-283 & $0 ; 80$ \\
\hline
\end{tabular}

Values are from all samples from both controls and manipulated mesocosms. Phase 0 samples were taken at the end of the low water table and phases 1-4 samples were taken during the high water table.

is accumulated because production exceeds decomposition [17], and with the coherent result of increasing decomposition when aeration of the peat increases [18]. We suggest that the increase in DON in pristine mesocosms (PrCtrl versus PrFluc; phase 1) was due to accelerated break down of organic macromolecules into smaller units during improved aerobic conditions, that is, during low water table, and this was seen as higher DON concentrations in peat water during the high water table. It is noteworthy that the DON concentrations at phase 1 in PrFluc were approximately at the same level than in DrCtrl and DrFluc mesocosms, where the aerobic conditions were better from the premise.

The substantial increase in $\mathrm{NH}_{4}{ }^{+}-\mathrm{N}$ concentrations during rewetting in pristine peat mesocosms also suggests accelerated mineralization due to preceding dry conditions. This is in line with the increase in DON, and it indicates that there were more organic molecules small enough to be mineralized into $\mathrm{NH}_{4}{ }^{+}-\mathrm{N}$ in PrFluc than in PrCtrl mesocosms. In drained peat mesocosms there were no changes neither in DON nor $\mathrm{NH}_{4}{ }^{+}-\mathrm{N}$ concentrations due to the experimental water table fluctuations indicating that the storage of easily available $\mathrm{N}$ for decomposers was small, and this is seen as a lower $\mathrm{NH}_{4}{ }^{+}-\mathrm{N}$ concentration than in the pristine peat.

In addition to the mechanism of increasing decomposition of organic macromolecules under aerobic conditions, explained in the previous paragraph, there are also other possible mechanisms explaining alterations in DON and $\mathrm{NH}_{4}{ }^{+}-\mathrm{N}$ concentrations under fluctuating water table. Knorr and Blodau [10] reported an increase in $\mathrm{NH}_{4}{ }^{+}-\mathrm{N}$ and $\mathrm{NO}_{3}{ }^{-}-\mathrm{N}$ concentrations during drought in pore water in peat mesocosms subjected to drying and rewetting. This supports our findings that the mineralization of organic matter accelerated during the low water table, causing an increase in $\mathrm{NH}_{4}{ }^{+}-\mathrm{N}$ concentration in pristine peat. On the contrary to our results and those of Knorr and Blodau [10], Dowrick et al. [19] reported decreases in $\mathrm{NH}_{4}{ }^{+}-\mathrm{N}$ concentrations after a severe drought implying that organisms responsible for decomposition are sensitive to soil moisture. Knorr and Blodau [10] found, however, that the $\mathrm{NH}_{4}{ }^{-}-\mathrm{N}$ and $\mathrm{NO}_{3}{ }^{-}-\mathrm{N}$ concentrations decreased after peat rewetting, but results of Kieckbusch and Schrautzer [20] give support to our rewetting results concerning increasing $\mathrm{NH}_{4}{ }^{+}-\mathrm{N}$ concentrations in pristine peat. They observed high ammonium discharge in autumn after a heavy rainfall from a eutrophic fen, a former agricultural land. Parallel with this, Arvola et al. [21] showed that summer and autumn nutrient loads (including total nitrogen, $\mathrm{NH}_{4}{ }^{+}-\mathrm{N}$, and $\mathrm{NO}_{3}{ }^{-}-\mathrm{N}$ ) correlate with precipitation in the Löytynoja catchment, to which the peatland area of our study belongs.

Interestingly, increasing $\mathrm{NH}_{4}{ }^{+}-\mathrm{N}$ could also affect DON concentrations, as it has been suggested that a release of DON from pristine and degraded peatlands is dependent on soil inorganic $\mathrm{N}$ rather than on organic matter content. The mechanism behind this is that inorganic $\mathrm{N}$ compounds increase microbial mobilization of these to amino acids [22]. This is consistent with our findings that DON concentrations increased in pristine peat simultaneously with $\mathrm{NH}_{4}{ }^{+}-\mathrm{N}$ concentrations. Respectively, when there was no effect of rewetting on DON in drained peat, no effect on $\mathrm{NH}_{4}{ }^{+}-\mathrm{N}$ was found. Both DON and $\mathrm{NH}_{4}{ }^{+}-\mathrm{N}$ might also have been simply released into water easier from pristine than from drained peat solid material. A runoff magnitude has been reported as an important increasing factor for DON release during autumn [23].

The increase of DON and $\mathrm{NH}_{4}{ }^{+}-\mathrm{N}$ in PrFluc mesocosms at the beginning of high water table period confirms that their increase/release was substantial as it clearly exceeded a potential dilution along with the spring water addition. In 


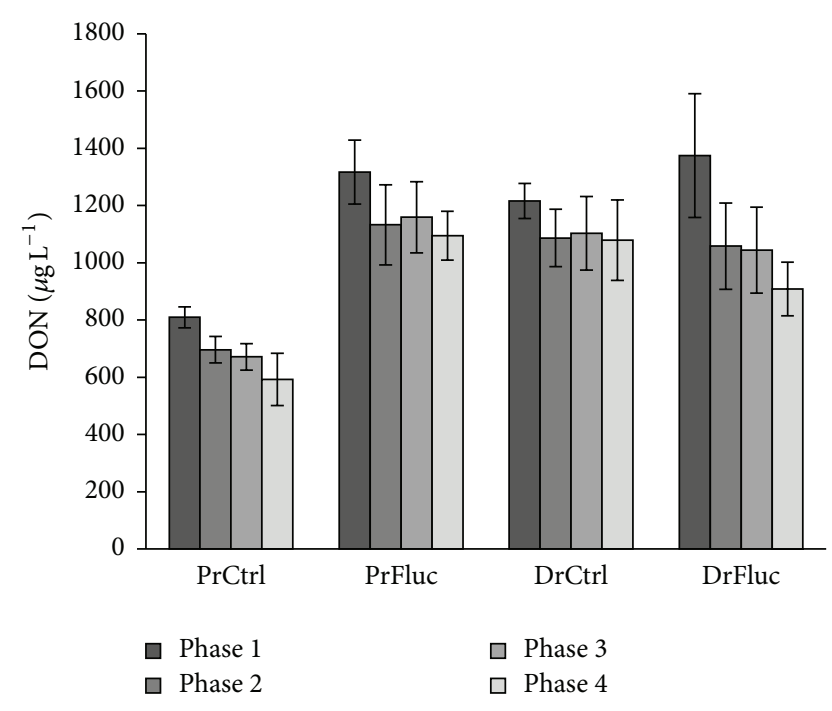

(a)

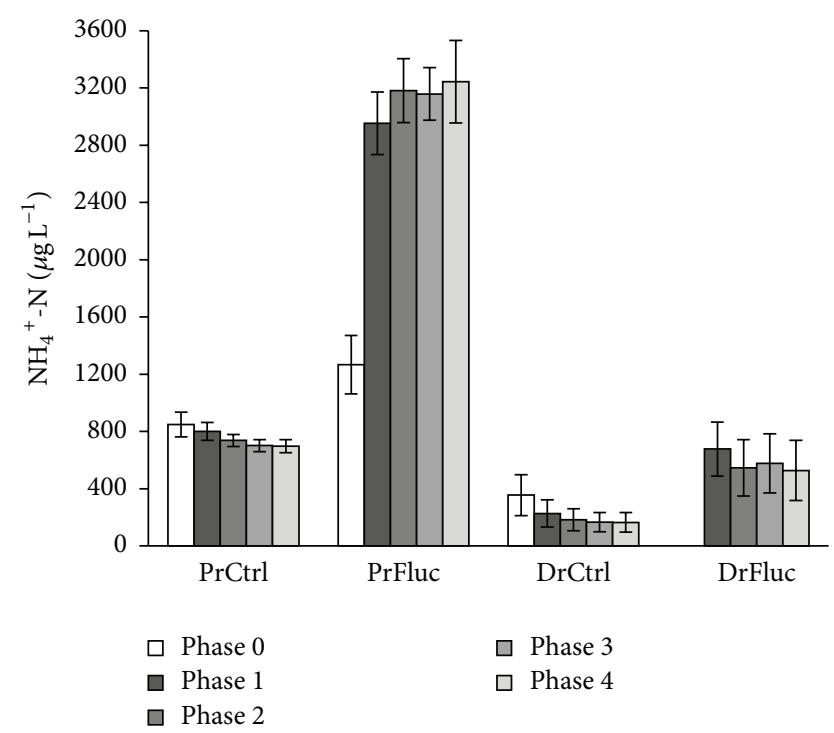

(b)

FIGURE 2: (a) Mean $( \pm$ SE) concentrations of DON in different experimental groups at phases $1-4 . N=5$ except at phases 3 and 4 in DrCtrl, where $n=4$. (b) Mean $( \pm \mathrm{SE})$ concentrations of $\mathrm{NH}_{4}{ }^{+}-\mathrm{N}$ in different experimental groups at phase 0 , that is, at the end of the low water table, and at phases 1-4, that is, during the high water table. $N=5$ except at phase 0 in PrFluc, where $n=4$, and in DrFluc, where $n=0$. See the results of the statistical analyses from Tables 2 and 3. $\mathrm{Pr}=$ pristine, $\mathrm{Dr}=$ drained, $\mathrm{Ctrl}=$ control, and Fluc $=$ fluctuating water table.

spite of the nonsignificant statistical result, it is important to note that the mean $\mathrm{NH}_{4}{ }^{+}-\mathrm{N}$ concentrations were higher in DrFluc in comparison to DrCtrl. Relative to the $\mathrm{NH}_{4}{ }^{+}-\mathrm{N}$ concentrations in controls, the response for fluctuating water table (Ctrl phase 1 versus Fluc phase 1) was only slightly stronger in pristine than in drained mesocosms. Higher DON concentrations in DrCtrl than in PrCtrl, as well as the lower $\mathrm{NH}_{4}{ }^{+}-\mathrm{N}$ concentration in DrCtrl than in PrCtrl, indicate that the peat types were different from the premise. High $\mathrm{NH}_{4}{ }^{+}-\mathrm{N}$ concentrations in PrFluc compared to DrFluc mesocosms were partly a result of initially higher ammonium concentrations and partly because of slightly stronger response to rewetting in pristine peat.

In general, the concentrations of $\mathrm{NO}_{2}{ }^{-}+\mathrm{NO}_{3}{ }^{-}-\mathrm{N}$ were low compared to $\mathrm{NH}_{4}{ }^{+}-\mathrm{N}$, and fluctuating water table did not significantly affect $\mathrm{NO}_{2}{ }^{-}+\mathrm{NO}_{3}{ }^{-}-\mathrm{N}$ concentrations. These results are divergent from those of Glatzel et al. [24]. They observed, on a restored drained bog, that an exceptionally hot and dry summer caused $\mathrm{NO}_{3}{ }^{-}-\mathrm{N}$ concentrations to rise and become a dominant fraction of mineral nitrogen. Rising $\mathrm{NO}_{3}{ }^{-}-\mathrm{N}$ concentrations due to drying and rewetting are also reported by Reiche et al. [11]. The high variability in $\mathrm{NO}_{2}{ }^{-}+$ $\mathrm{NO}_{3}{ }^{-}-\mathrm{N}$ concentrations in both peat types of our study can, at least partly, be explained by the relatively high volumes of the added spring water containing higher concentrations of $\mathrm{NO}_{2}{ }^{-}+\mathrm{NO}_{3}{ }^{-}-\mathrm{N}$ compared to the soil water in the mesocosms. This also may have homogenized the results of $\mathrm{NO}_{2}{ }^{-}+\mathrm{NO}_{3}{ }^{-}-\mathrm{N}$ concentrations of the experimental groups, and the possible effects of drying and rewetting have become unnoticeable.

Our results suggest that rewetting event successive to drought may release high quantities of dissolved organic nitrogen and ammonium into soil water of pristine boreal peatlands. Drained peatlands, instead, release nitrogen compounds more evenly in spite of fluctuating water table. Peatlands cover substantial areas in boreal landscape and particularly in Finland where there are 751000 ha of oligoombrotrophic large shrub or Eriophorum vaginatum dominated peatlands [13]. Therefore, we assume that similar changes in hydrological conditions, as we tested in our study, can cause major changes in nitrogen transport to the rivers and lakes in large areas.

\section{Acknowledgments}

This study was funded by the Academy of Finland (Projects "Processes Controlling DOC-fluxes in Boreal Catchments" and "Processes and Organisms in Nitrification"), Onni ja Hilja Tuovinen Foundation, and Finnish Cultural Foundation, Päijät-Häme Regional fund. Special thanks to assistants Marja Kosme and Saara Rinne, laboratory staff Jaakko Vainionpää and Riitta Ilola, and research technicians Marja-Leena Vitie and Jussi Vilén at Lammi Biological Station.

\section{References}

[1] M. C. Serreze and J. A. Francis, "The arctic amplification debate," Climatic Change, vol. 76, no. 3-4, pp. 241-264, 2006.

[2] J. Pastor, J. Solin, S. D. Bridgham et al., "Global warming and the export of dissolved organic carbon from boreal peatlands," Oikos, vol. 100, no. 2, pp. 380-386, 2003.

[3] E. Kjellström, "Recent and future signatures of climate change in Europe," Ambio, vol. 33, no. 4-5, pp. 193-198, 2004.

[4] K. Jylhä, H. Tuomenvirta, and K. Ruosteenoja, "Climate change projections for Finland during the 21st century," Boreal Environment Research, vol. 9, no. 2, pp. 127-152, 2004.

[5] M. Stieglitz, J. Shaman, J. McNamara, V. Engel, J. Shanley, and G. W. Kling, "An approach to understanding hydrologic 
connectivity on the hillslope and the implications for nutrient transport," Global Biogeochemical Cycles, vol. 17, no. 4, pp. 16-1, 2003.

[6] K. Moore, E. Jennings, N. Allott et al., "Modelling the effects of climate change on the supply of inorganic nitrogen," in The Impact of Climate Change on European Lakes, D. G. George, Ed., Aquatic Ecology Series 4, pp. 179-197, Springer Science+Business Media B.V., 2010.

[7] M. Holmberg, M. Forsius, M. Starr, and M. Huttunen, "An application of artificial neural networks to carbon, nitrogen and phosphorus concentrations in three boreal streams and impacts of climate change," Ecological Modelling, vol. 195, no. 1-2, pp. 5160, 2006.

[8] B.-L. Hu, L.-D. Shen, X.-Y. Xu, and P. Zheng, "Anaerobic ammonium oxidation (anammox) in different natural ecosystems," Biochemical Society Transactions, vol. 39, no. 6, pp. 1811-1816, 2011.

[9] S. D. Bridgham, K. Updegraff, and J. Pastor, "Carbon, nitrogen, and phosphorus mineralization in northern wetlands," Ecology, vol. 79, no. 5, pp. 1545-1561, 1998.

[10] K.-H. Knorr and C. Blodau, "Impact of experimental drought and rewetting on redox transformations and methanogenesis in mesocosms of a northern fen soil," Soil Biology and Biochemistry, vol. 41, no. 6, pp. 1187-1198, 2009.

[11] M. Reiche, A. Hädrich, G. Lischeid, and K. Küscl, "Impact of manipulated drought and heavy rainfall events on peat mineralization processes and source-sink functions of an acidic fen," Journal of Geophysical Research G, vol. 114, no. 2, Article ID G02021, 2009.

[12] D. Zak and J. Gelbrecht, "The mobilisation of phosphorus, organic carbon and ammonium in the initial stage of fen rewetting (a case study from NE Germany)," Biogeochemistry, vol. 85, no. 2, pp. 141-151, 2007.

[13] E. Ylitalo, Ed., Finnish Statistical Yearbook of Forestry, Finnish Forest Research Institute. Vammalan Kirjapaino Oy, Sastamala, Finland, 2010, Finnish.

[14] S. Eurola, A. Huttunen, and K. Kukko-oja, Oulanka reports 14-Suokasvillisuusopa, University of Oulu, Oulanka Biological Station, Oulu, Finland, 1995, Finnish.

[15] E. Lappalainen, C.-G. Stén, and J. Häikiö, Turvetutkimusten MaastO-Opas, Opas N:O 12, Geologian tutkimuskeskus, Espoo, Finland, 1984, Finnish.

[16] Anonymous, SAS/STAT, 9.2 User's Guide, SAS Institute, Cary, NC, USA, 2008.

[17] R. Clymo, “The Limits To Peat Bog Growth," Philosophical Transactions of the Royal Society of London, vol. 303, no. 1117, pp. 605-654, 1984.

[18] J. J. M. Geurts, A. J. P. Smolders, A. M. Banach, J. P. M. van de Graaf, J. G. M. Roelofs, and L. P. M. Lamers, "The interaction between decomposition, net $\mathrm{N}$ and $\mathrm{P}$ mineralization and their mobilization to the surface water in fens," Water Research, vol. 44, no. 11, pp. 3487-3495, 2010.

[19] D. J. Dowrick, S. Hughes, C. Freeman, M. A. Lock, B. Reynolds, and J. A. Hudson, "Nitrous oxide emissions from a gully mire in mid-Wales, UK, under simulated summer drought," Biogeochemistry, vol. 44, no. 2, pp. 151-162, 1999.

[20] J. J. Kieckbusch and J. Schrautzer, "Nitrogen and phosphorus dynamics of a re-wetted shallow-flooded peatland," Science of the Total Environment, vol. 380, no. 1-3, pp. 3-12, 2007.

[21] L. Arvola, M. J. Järvinen, and I. Hakala, "Nutrient export from small boreal catchment areas: the influence of annual and seasonal hydrology," in International Association of Theoretical and
Applied Limnology_Proceedings, J. Jones, Ed., vol. 29, pp. 20312034, 2006.

[22] K. Kalbitz and S. Geyer, "Different effects of peat degradation on dissolved organic carbon and nitrogen," Organic Geochemistry, vol. 33, no. 3, pp. 319-326, 2002.

[23] R. Cooper, V. Thoss, and H. Watson, "Factors influencing the release of dissolved organic carbon and dissolved forms of nitrogen from a small upland headwater during autumn runoff events," Hydrological Processes, vol. 21, no. 5, pp. 622-633, 2007.

[24] S. Glatzel, S. Lemke, and G. Gerold, "Short-term effects of an exceptionally hot and dry summer on decomposition of surface peat in a restored temperate bog," European Journal of Soil Biology, vol. 42, no. 4, pp. 219-229, 2006. 

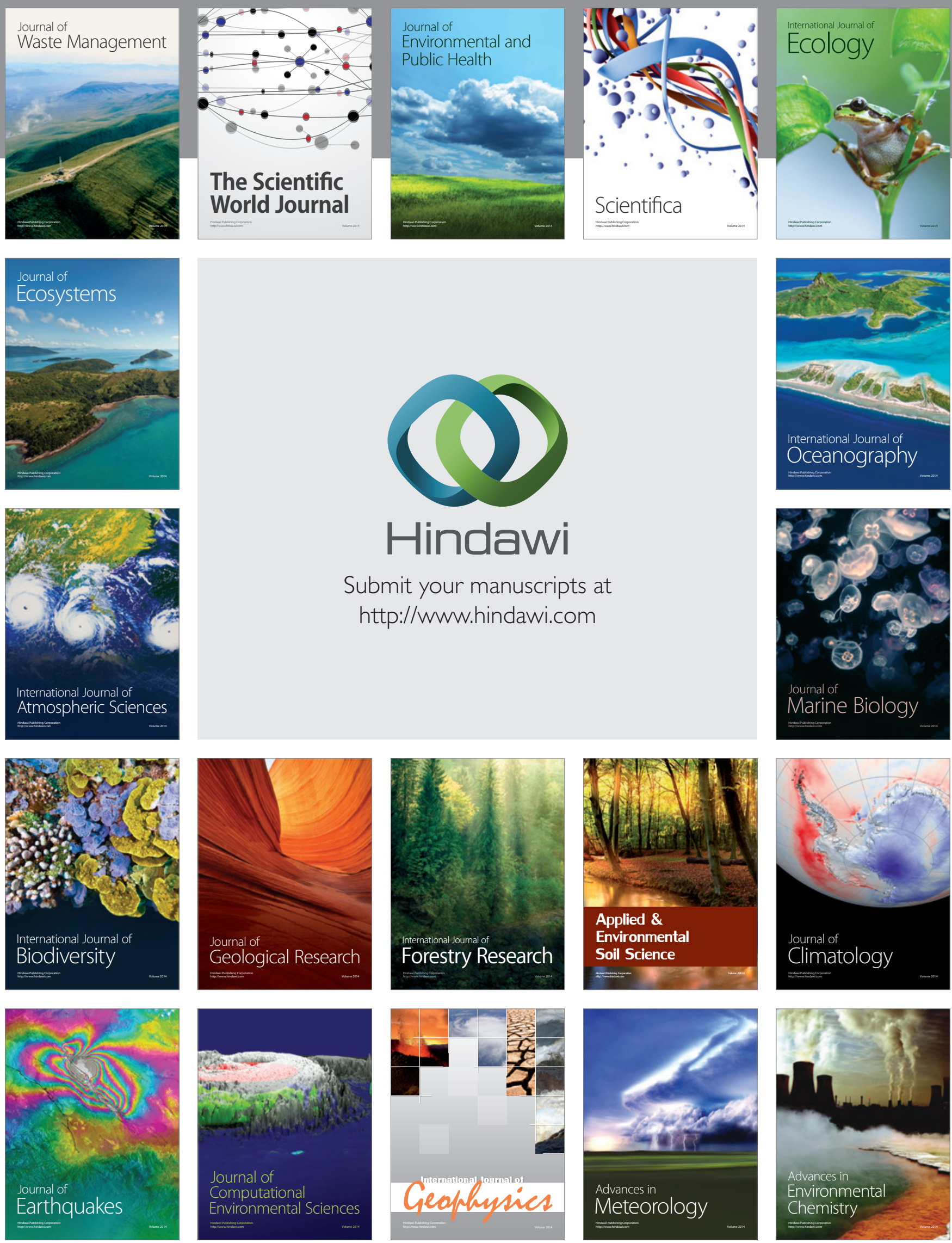